Dokuz Eylül Üniversitesi-Mühendislik Fakültesi Fen ve Mühendislik Dergisi

Cilt 20, Sayı 59, Mayıs, 2018
Dokuz Eylul University-Faculty of Engineering Journal of Science and Engineering Volume 20, Issue 59, May, 2018

DOI: $10.21205 /$ deufmd. 2018205937

\title{
Sürtünme Karıştırma Kaynağıyla Birleştirilen St37/St52 Levhaların Mikroyapı Karakterizasyonu ve Mekanik Özellikleri
}

\section{Güven İPEKOĞLU ${ }^{* 1}$, Tevfik KÜÇÜKÖMEROĞLU², Semih M.AKTARER ${ }^{3}$, D. Murat SEKBAN $^{4}$, Gürel ÇAM 1}

1İskenderun Teknik Üniversitesi, Mühendislik ve Doğa Bil. Fakültesi, Makina Müh. Böl., 31200, İskenderun, Hatay (ORCID: https://orcid.org/0000-0001-6233-4848, ORCID: https://orcid.org/0000-0003-0222-9274)

${ }^{2}$ Karadeniz Teknik Üniversitesi, Mühendislik Fakültesi, Makina Mühendisliği Bölümü, 61080, Trabzon (ORCID: https://orcid.org/0000-0002-4392-9966)

${ }^{3}$ Recep Tayyip Erdoğan Üniversitesi, Teknik Bilimler Meslek Yüksekokulu, Otomotiv Teknolojisi Programı, 53100, Rize (ORCID: https://orcid.org/0000-0001-5650-7431) 4Karadeniz Teknik Üniversitesi, Deniz Bilimleri Fak., Gemi İnşaatı ve Gemi Makineleri Müh. Böl., 61080, Trabzon (ORCID: https://orcid.org/0000-0002-7493-1081)

(Alınış / Received: 01.08.2017, Kabul / Accepted: 08.12.2017, Online Yayınlanma / Published Online: 15.05.2018)

Anahtar Kelimeler Özet: Sürtünme Karıştırma Kaynağı (SKK), geçtiğimiz otuz yılda Sürtünme Karıştırma Kaynağl,

St37,

St52,

Farklı Bağlantılar, İçyapı,

Mekanik Performans çeşitli endüstrilerde alüminyum alaşımlarına başarı ile uygulanmaktadır. Fakat çeliklerin kaynağında, bu işlemlerde açı̆̆a çıkan sıcaklıklara dayanabilecek karıștırıcı takımlardaki kısıtlamalarından ötürü, geniş çaplı olarak kullanılamamaktadır. $\mathrm{Bu}$ çalışmada, SKK ile birleştirilen St37/St52 farklı düşük karbonlu çeliklerin mekanik özellikleri ve içyapısındaki değişimlerin araştırılması amaçlanmıştır. Elde edilen sonuçlara göre, kaynak bölgesi, Widmanstatten ferrit, sementit kümesi içeren veya içermeyen ferrit ve tane sınırı ferriti gibi karmaşık içyapılardan oluşmaktadır. Karıştırma bölgesindeki en yüksek sertlik, katı hal dönüşümleri ve tane incelmesinden dolayı yaklaşık 347 HV'ye ulaşmaktadır. Birleştirilen levhalar, 389 MPa'lık bir çekme mukavemeti değeri sergilemiş olup, bu değer sırasıyla St37 ve St52 çeliklerinin çekme mukavemet değerleri olan 373 ve $526 \mathrm{MPa}$ 'n arasında bir değerdir. Bağlantının akma dayanımı $272 \mathrm{MPa}$ olarak bulunmuştur. $\mathrm{Bu}$ değer de, her iki ana malzemenin akma dayanımlarının arasında bir değerdir.

\section{Microstructural Characterization and Mechanical Properties of St37/St52 Plates Joined by Friction Stir Welding}

\begin{tabular}{ll}
\hline Keywords & Abstract: Friction stir welding (FSW) has been applied successfully \\
Friction Stir & to aluminum alloys in several industries over the past three decades. \\
Welding, & $\begin{array}{l}\text { However, it is not widely used in joining of steels due to the } \\
\text { St37, }\end{array}$ \\
limitations of the tool materials which can withstand the temperatures \\
Dissimilar joints, & $\begin{array}{l}\text { experienced. The aim of this study is to investigate the change in the } \\
\text { mechanical properties and the microstructures of FSW'ed St37/St52 }\end{array}$
\end{tabular}


Microstructure, Mechanical Performance dissimilar low carbon steels joints. The results obtained indicate that the weld region is comprised of complex microstructures such as Widmanstatten ferrite, ferrite with or without carbide aggregates and grain boundary ferrite. The maximum hardness in the stir zone reached up to about $347 \mathrm{HV}$ due to the solid state transformations and grain refinement. The welded plates displayed an ultimate tensile strength of about $389 \mathrm{MPa}$, which lies between the ultimate tensile strength of St37 and St52 steels, 373 and $526 \mathrm{MPa}$, respectively. The yield strength of the joint was found to be about $272 \mathrm{MPa}$. This value is also a value between those of the base plates.

\begin{abstract}
*Sorumlu yazar: guven.ipekoglu@iste.edu.tr

\section{Giriş}

Sürtünme Karıștırma Kaynağı (SKK), kaynağı güç yüksek mukavemetli Alalaşımlarının benzer ve farklı kombinasyonları da dâhil olmak üzere, aynı türden ve farklı türden malzemelerin kaynağında ve hatta Alalaşımlarının başka türden malzemelerle kaynağında başarı ile kullanılabilen bir katı hal kaynak yöntemidir [1-6]. Ancak, aslında SKK yöntemi Al-alaşımları [5-14], Mg-alaşımları $[4,15-17]$ ve $\mathrm{Cu}$ alaşımlarının $[4,18-21]$ kaynağında bașarı ile kullanılmakla beraber, mevcut karıştırıcı takım malzemelerindeki kısıtlamalardan ötürü yüksek ergime dereceli malzemelerin kaynağı söz konusu olduğunda geniş bir kullanım alanına sahip değildir $[3,4,22,23]$.
\end{abstract}

Öte yandan, SKK ile birleştirilen çelik yapılarda, bu kaynak tekniğinin bir getirisi olarak, çarpılma ve artık gerilme oluşumu sınırlıdır. Ayrıca, ısı etkisi altındaki bölgedeki (IEB) tane büyümesi ise düşük seviyelerdedir $[4,22]$. $\mathrm{Bu}$ nedenle, pek çok araştırmacı çeliklerin bu katı hal kaynak tekniği ile birleştirilmesi konusunda çalışmalar yürütmektedir [4].

$\mathrm{Bu}$ doğrultuda, araştırmacılar SKK yönteminin düşük karbonlu çelikler [23, 24], yumuşak çelik [25], yüksek karbonlu çelik [26], düşük alaşımlı orta karbonlu çelik [27] ve farklı karbon içerikli çeliklere [28, 29] uygulanabilirliğini araştırmışlardır. Ayrıca, kaynaklı bağlantıların içyapısını ve mekanik özelliklerini incelemişlerdir. Örneğin, Fujii vd. [23] üç farklı çeliğin (IF çeliği, S12C ve S35C) farkl kaynak parametreleri kullanılarak kaynak bölgesinde herhangi bir dönüşüm olmadan SKK ile başarılı bir şekilde birleştirildiğini ve kaynak işlemi sırasında ölçülen maksimum sıcaklığın yaklaşık $650^{\circ} \mathrm{C}$ olarak ölçüldüğünü rapor etmişlerdir. $\mathrm{Bu}$ sonuçlar, bu çeliğin birleştirme işlemlerinde SKK'nın rahatlıkla kullanılabileceğini göstermektedir. Hatta, Cui vd. [26] SKK yöntemi ile yüksek karbonlu bir çeliğin bile kaynak edilebileceğini göstermişlerdir. Ancak, farklı iki demir esaslı malzemenin birbiriyle SKK yöntemi kullanılarak birleștirilmesi üzerine çok az sayıda çalışma yapılmıştır [30-32].

Pek çok endüstriyel uygulama, düşük maliyetli üretim ve yüksek tasarım verimliliği açısından, farklı çeliklerin birbiriyle birleştirilmesini gerektirir. $\mathrm{Bu}$ nedenle, farklı çeliklerden oluşan SKK ile birleştirilmiş bağlantıların iç yapısal ve mekaniksel özelliklerinin tam olarak anlaşılabilmesi açısından bu konuda daha fazla çalışmaya ihtiyaç vardır. $\mathrm{Bu}$ doğrultuda, bu çalışma kapsamında, karbon oranları sırasıyla \% 0,17 ve $\%$ 0,25 ve dolayısıyla içyapıları belirgin bir şekilde farklı olan St37 (S235JR) ve St52 (S355JR) çelik levhalar SKK yöntemi ile birleştirilmiştir. $\mathrm{Bu}$ çelikler gemi gövdeleri ve köprülerin inşasında 
G. İpekoğlu vd. / Sürtünme Karıștırma Kaynağıyla Birleştirilen St37/St52 Levhaların Mikroyapı Karakterizasyonu ve Mekanik Özellikleri

kullanılmaktadır [33-35]. Elde edilen kaynaklı bağlantının farklı bölgelerindeki içyapılar ve kaynaklı bağlantının mekanik özellikleri detaylı bir şekilde araştırılmıştır.

\section{Materyal ve Metot}

$\mathrm{Bu}$ çalışmada, $200 \mathrm{x} 60 \mathrm{x} \quad 4 \mathrm{~mm}$ ebatlarında hazırlanmıș St37 (S235JR) ve St52 (S355JR) çelik levhalar SKK ile alın alına birleştirilmiştir. SKK işlemleri, 18 $\mathrm{mm}$ omuz çapına ve $3,8 \mathrm{~mm}$ pim uzunluğuna sahip tungsten karbür (WC) esaslı konik karıștırıcı uç (Şekil 1) kullanılarak gerçekleştirilmiştir. Konik pimin dip çapı $7 \mathrm{~mm}$ ve tepe çapı 5 mm'dir. Kullanılan karıştırıcı uç, ticari olarak temin edilen $18 \mathrm{~mm}$ çapında tungsten karbür çubuktan elmas taș kullanılarak alet bileme tezgâhında imal edilmiştir. SKK işleminde ön çalışmalardaki tecrübeye dayanarak hatasız kaynak elde etmek amaciyla devir hızı $630 \mathrm{~min}^{-1}$ ve ilerleme hızı 65 mm.min ${ }^{-1}$ olarak seçilmiştir. Batıcı uç eğim açısı $3^{\circ}$ olarak kullanılmış olup, 10 kN'luk yük etkisi altında yük kontrollü kaynak işlemi gerçekleştirilmiştir.

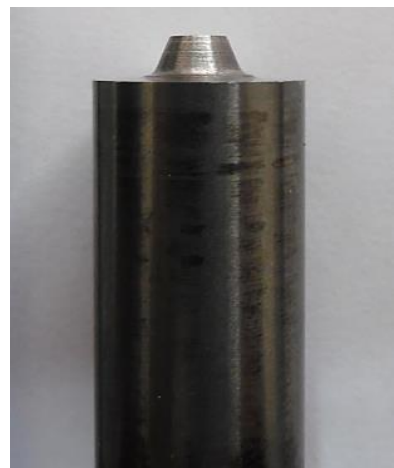

Şekil 1. SKK işlemlerinde kullanılan karıștırıcı uç.

Çekme deneyinde kullanılmak üzere, ana malzemelerden ve kaynaklı birleştirmeden kaynağa dik yönde ve indirgenmiş kesit ölçüleri 2 × 5 × 26 mm olan küçük boyutta (standart dişı) üçer adet çekme deneyi numunesi ve kaynaklı bağlantıdan her iki ana malzemeyi de kapsayan bir adet metalografi numunesi çlkarılmıştır. $\mathrm{Bu}$ sayede kaynak bölgesinin çekme mukavemeti, akma dayanımı ve uzama özelliklerinin belirlenmesi amaçlanmıştır. Çekme testleri $5 \times 10^{-4} \mathrm{~s}^{-1}$ lik gerinim etkisi altinda Instron 3382 video ekstansometreli elektro-mekanik yük üniteli çekme cihazında test edilmiştir.

Metalografi numuneleri standart numune hazırlama prosedürünü takiben $\% 2$ nital solüsyonu içerinde $20 \mathrm{~s}$ süreyle dağlanmıştır. Çalışmada kullanılan ana malzemeler ve kaynak bölgesi Zeiss optik metal mikroskobu kullanılarak detaylı bir șekilde incelenmiștir. Çalıșmada kullanılan ana malzemelerin tane boyutu ile içyapılarındaki ferrit ve perlit fazlarının oranları da tespit edilmiştir. $\mathrm{Bu}$ işlemler için ImageJ görüntü işleme programı kullanılmıştır. Tane boyutu ölçümü kesişim yöntemine göre, ferlit ve perlit fazı oranlarının tespiti ise ilgili mikroyapı görüntüsünün toplam alanı içindeki söz konusu faz alnının hesaplanmasıyla yapılmıştır. Mikrosertlik ölçümleri, 300 g yük etkisi altında, Vickers yöntemi kullanılarak gerçekleștirilmiş ve kaynaklı bağlantıların sertlik profilleri çıkarılmıştır. Sertlik ölçümleri kaynak merkezinin ortasından olacak şekilde yatay yönde gerçekleștirilmiştir. $\mathrm{Bu}$ sayede kaynağın farklı bölgelerinde söz konusu olan sertlik değişimleri belirlenmeye çalışılmıştır. Ayrıca, kaynaklı numunenin yine kaynak merkezinden olmak üzere düşey yönde de sertlik ölçümleri gerçekleştirilmiş ve numunenin düşey yöndeki sertlik profili çlkarılmıştır. Bu sayede, kaynak üst yüzeyinden kaynak kök kısmına doğru sertlik değişiminin nasıl gerçekleştiği belirlenmiştir.

\section{Araştırma Bulguları ve Tartışma 3.1. İçyapı Özellikleri}

Çalışmada kullanılan St37 ve St52 çelik levhaların optik mikroskop görüntüleri 
G. İpekoğlu vd. / Sürtünme Karıștırma Kaynağıyla Birleştirilen St37/St52 Levhaların Mikroyapı Karakterizasyonu ve Mekanik Özellikleri

sırasıyla Şekil 2 (b) ve (c)'de gösterilmiştir. St37 ve St52 çelik levhaların her ikisi de, ferrit (beyaz renkli) ve perlit (siyah renkli) fazlarından oluşan tipik düşük karbonlu bir çelik yapısına sahiptir. Bu çeliklerin içyapısı, temel olarak $14 \mu \mathrm{m}$ ile $18 \mu \mathrm{m}$ arasında değișen eș eksenli ferrit taneleri ve değişen oranlarda perlit fazı içermektedir. Mikroyapıdaki perlit fazının oranı St37'de \%9, St52'de ise belirgin bir şekilde daha yüksek olup \%18'dir. St52'nin içindeki perlit fazı hadde etkisinden ötürü hadde yönünde uzamış olarak bulunmaktadır (Şekil 2(c)). Dolayısıyla, bu çalışmada kullanılan iki farklı çeliğin içyapısı belirgin olarak birbirinden farklıdır. SKK sonrası ortaya çıkan kaynak bölgesi, alüminyum gibi yeniden kristalleşmenin zor olduğu malzemelerde, üç farklı bölgeden oluşmaktadır. $\mathrm{Bu}$ bölgeler: dinamik olarak yeniden kristalleşen bölge (DKB), termo-mekanik olarak etkilenen bölge (TMEB) ve ısının etkisi altındaki bölgedir (IEB) [4, 5, 36]. Öte yandan, çelik, titanyum, Cu-alaşımları gibi yeninden kristalleşmenin kolay olduğu malzemelerdeki kaynak bölgesi ise, DKB ve IEB olmak üzere sadece iki bölgeden oluşur [5]. Bu gibi alaşımlarda belirgin bir TMEB gözlenmemektedir (Şekil 2(a)).
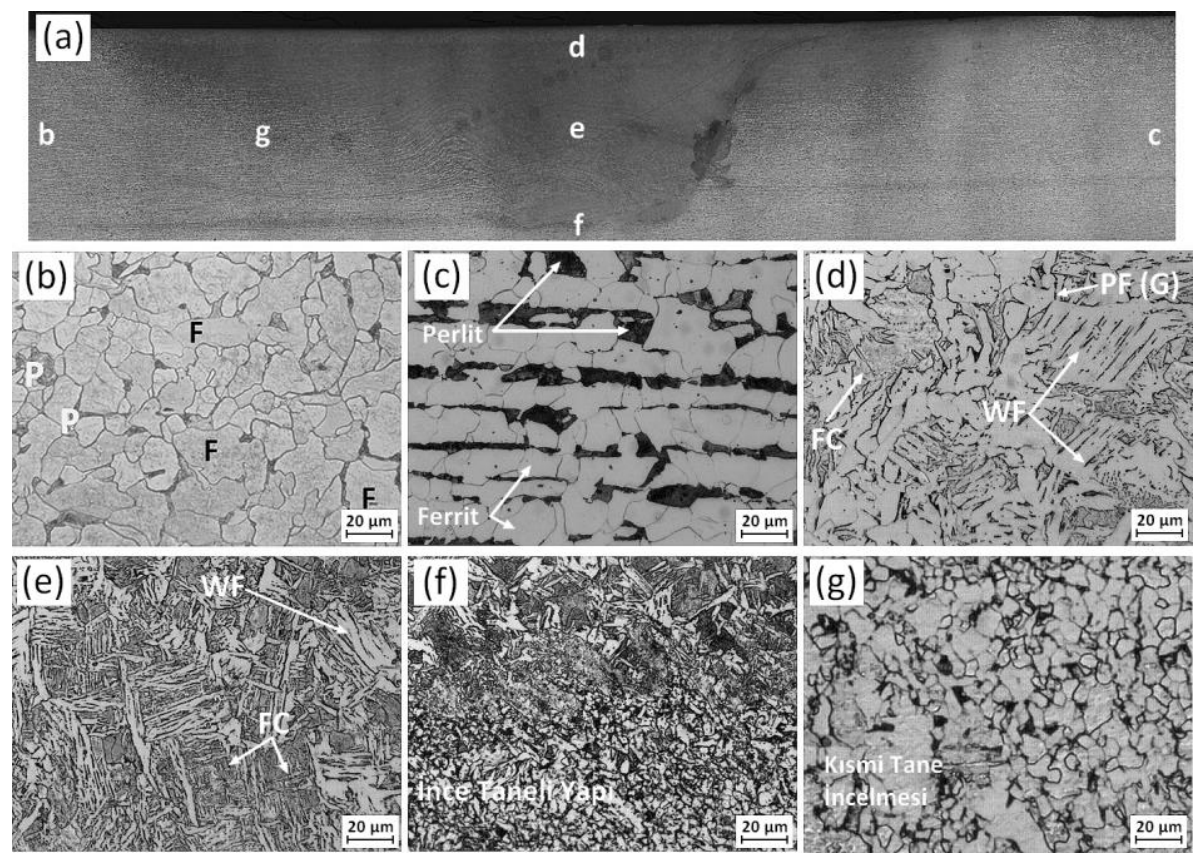

Şekil 2. SKK ile birleştirilen St37/St52 çelik bağlantının optik mikroskop görüntüleri:

(a) Kaynak kesitinin şematik genel görüntüsü, (b) St37 ana malzeme, (c) St52 ana malzeme,

(d) karıștırma bölgesinin üst yüzeyi, (e) karıștırma bölgesinin merkezi, (f) karıștırma bölgesi kök bölgesi, g) yığma tarafındaki IEB'deki geçiş bölgesi

Dinamik olarak yeniden kristalleșen bölgede, karıştırıcı takımın dönme hareketinden ve sürtünmeden kaynaklı olarak ortaya çıkan ısıdan dolayı sıcak deformasyon söz konusudur [25]. Bu nedenle, bu bölgedeki içyapı Widmanstatten ferrit (WF), sementit kümesi içeren ya da içermeyen ferrit (FC) ve tane sınırı ferriti (PF (G)) gibi karmaşık bir yapıdan oluşmaktadır (Şekil 2 (d), (e) ve (f)). Ancak tane sinırı ferriti içermeyen Widmanstatten yapısı (Şekil 2 (e)) bu bölgenin içyapısında baskın durumdadır. Bu sebepten ötürü, kaynak 
G. İpekoğlu vd. / Sürtünme Karıștırma Kaynağıyla Birleştirilen St37/St52 Levhaların Mikroyapı Karakterizasyonu ve Mekanik Özellikleri

bölgesinde Widmanstatten ferritin olduğu kısımlarda soğuma hızının düşük olduğu düșünülmektedir. Çünkü Widmanstatten ferrit karakteristik olarak beynit veya martenzite oranla göreceli olarak daha düşük soğuma hızlarında oluşmaktadır. Ayrıca, bu yapının yüksek en/boy oranına sahip olduğu görülmektedir (Şekil 2 (e)) [37]. Karıştırma bölgesinde karıștırıcı takımın sebep olduğu şiddetli plastik deformasyon ve isı girdisi neticesinde perlit çözünmesi söz konusu olmuș ve bu bölgede lameller yapıda olmayan ve ferrit fazı içerisinde dağılmış sementit partiküllerinden oluşan, perlitik bir yapı gözlenmiştir (Şekil 2 (d) ve (e)). Ayrıca, ferrit fazı kaynak sonrası soğuma sırasındaki dönüşüm sıcaklığında, kaynak esnasında oluşan östenit tane sınırlarında tane sinırı ferriti olarak çökelmiştir (Şekil 2 (d)) [37].

Şekil 2 (f)'den görüldüğü üzere kaynaklı numunenin kök kısmında eş eksenli ve çok ince taneli (yaklaşık $1 \mu \mathrm{m}$ iriliğinde) bir yapı mevcudiyeti söz konusu olmuştur. $\mathrm{Bu}$ ince taneli yapının oluşma sebebi, bu bölgedeki malzemenin, pimin ucu ile destek tablası arasında sıkışarak çok yüksek derecede plastik deformasyona maruz kalmasıdır. Ayrıca, karıştırma bölgesindeki malzeme yapısı pimin açısal hızına ve pim etrafındaki karıştırma etkisine bağlıdır. Literatürde de kaynak kök bölgesindeki içyapının kaynak merkezindeki yapıya nazaran daha homojen ve daha ince taneli olduğu rapor edilmiştir [38]. Şekil 2 (g)'den görüldüğü üzere IEB eş eksenli ince taneli ferrit ve ince taneli perlit ile kaba taneli ferrit tanelerinden oluşmaktadır. $\mathrm{Bu}$ bölgede kaynak sıranda oluşan maksimum sicaklık tane yapısının ince olduğu $\quad \alpha+\gamma \quad$ bölgesine karşılık gelmektedir. Dolayısıyla, kaynak sonrası soğuma sonucu içyapıda kısmi tane incelmesi söz konusu olmuştur.

\subsection{Mekanik Özellikler}

Şekil 3, sürtünme karıştırma kaynaklı numunenin kaynak bölgesinin yatay ve düşey doğrultudaki sertlik profillerini göstermektedir. Yatay doğrultudaki sertlik profili, kaynak kesitinin tam ortasından kaynak yüzeyinden $2 \mathrm{~mm}$ aşağıda olacak şekilde yapılan sertlik ölçümlerinden elde edilmiștir (Şekil 3 (a)). Düşey doğrultudaki sertlik profili ise kaynak merkezinden düşey yönde ölçülen sertlik değerlerinden elde edilmiştir.

Sertlik profillerinden görüleceği üzere St37 ve St52 ana malzemelerin sertlik değerleri sırasıyla $137 \mathrm{HV}_{0,3}$ ve 180 $\mathrm{HV}_{0,3}$ 'dür. SKK'lı numunenin yatay sertlik profili değerleri $137 \mathrm{HV}_{0,3}$ ve $347 \mathrm{HV}_{0,3}$ arasında değişmektedir (Şekil 3 (b)). Ölçülen en yüksek sertlik değeri (347 $\mathrm{HV}_{0,3}$ ) kaynak merkezinden yaklaşı 3 mm uzaktaki süpürme (ilerleme) tarafında tespit edilmiştir. Bunun sebebinin bu bölgede tespit edilmiş olan ince lamelli WF ve/veya ferrit fazı içerisinde kümelenmiş sementit fazı olduğu düşünülmektedir.

Şekil 3 (c) sertlik ölçümü yapılan bazı noktaların içyapısını göstermektedir. En yüksek sertlik değerinin tespit edildiği noktadaki içyapı Şekil 2 (e)'deki içyapıya benzemekte olup bu bölge ince taneli WF ve sementit çökeltili FC'den oluşmaktadır. Bu içyapı da maksimum sertliği açıklamaktadır.

Düşey doğrultuda ölçülen sertlik değerleri ise $167 \mathrm{HV}_{0,3}$ ile $300 \mathrm{HV}_{0,3}$ arasında değişmektedir (Şekil 3 (d)). En yüksek sertlik değeri kaynak merkezinde ölçülmüş olup buradaki içyapı da (Şekil 3 (c)) yine Şekil 2 (e)'ye benzerlik göstermekte ve ince taneli WF ve sementit çökeltili FC'den oluşan bu içyapı yüksek sertlik değerini açıklamaktadır. En düşük sertlik değeri ise $167 \mathrm{HV}_{0,3}$ olarak kaynak yüzeyine yakın bölgede tespit edilmiştir. $\mathrm{Bu}$ düşük sertliğin 
G. İpekoğlu vd. / Sürtünme Karıştırma Kaynağıyla Birleştirilen St37/St52 Levhaların Mikroyapı Karakterizasyonu ve Mekanik Özellikleri

sebebi, WF'nin bu bölgede iri taneli olması ve FC'nin ise sayısın az olmakla beraber sementit çökeltilerinin tane içindeki yoğunluğunun düşük mertebede kalmasıdır (Şekil 2 (d) ve Şekil 3 (c)). Ayrıca, bu ölçülen sertlik değeri yaklaşık olarak St52 ana malzeme sertlik değerine $\left(180 \mathrm{HV}_{0,3}\right)$ yakındır.
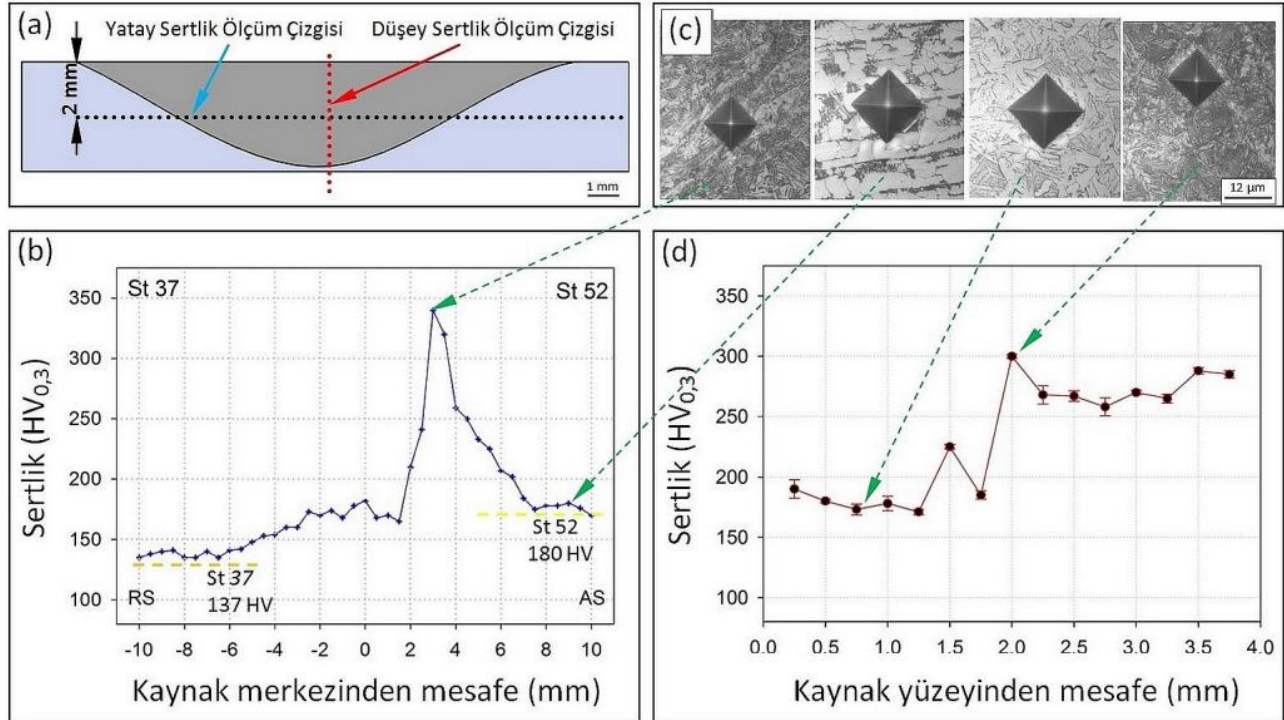

Şekil 3. (a) Sertlik ölçüm çizgilerini gösteren kaynak kesitinin șematik gösterimi, (b) sürtünme karıştırma kaynaklı levhanın yatay sertlik profili (c) sertlik ölçüm noktalarının bazılarının bulunduğu noktalardaki içyapı, (d) düşey sertlik profili.

Çekme deneyi sonucunda, St37 ana malzeme belirgin bir akma noktası gösterirken ana malzeme St52 belirgin bir akma noktası sergilememiş olup, akma dayanımları sırasıyla $250 \mathrm{MPa}$ ve $337 \mathrm{MPa}$ olarak ölçülmüştür. Diğer taraftan, kaynaklı numunede de belirgin bir akma noktası gözlenmemiş ve bu numunenin akma dayanımının (yaklașık olarak $272 \mathrm{MPa}$ ) her iki ana malzemenin akma dayanımlarının arasında olduğu tespit edilmiştir. Çekme mukavemetleri incelendiğinde de, kaynaklı numunenin 389 MPa'llk çekme dayanımı sergilediği ve bu değerin de St37 ana malzemenin çekme dayanımından (373 $\mathrm{MPa})$ yüksek, St52 ana malzeme çekme dayanımından (526 MPa) ise oldukça düşük olduğu görülmektedir (Şekil 4 ve Tablo 1). Diğer taraftan, ana malzemelerde çekme deneyi sırasında düşük oranda pekleşme (deformasyon sertleşmesi) gerçekleşmiş ve bu numuneler yüksek bir uzama değeri sonrası kopmuşlardır.

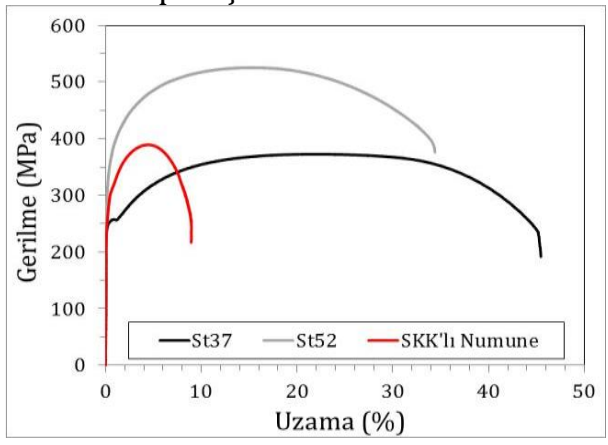

Şekil 4. Ana malzemeler ile kaynaklı numunenin gerilme-uzama eğrileri.

St37 ve St52 ana malzemelerin uzama değerleri sırası ile \%45 ve \%35 olarak tespit edilmiştir. Buna karşılık SKK ile birleștirilen numunenin \% uzama değeri ana malzeme uzama değerlerinin çok altında kalmış ve $\% \quad 9$ olarak ölçülmüştür. Uzama değerindeki bu düşüşün sebebi, kaynak bölgesindeki faz 
G. İpekoğlu vd. / Sürtünme Karıștırma Kaynağıyla Birleştirilen St37/St52 Levhaların Mikroyapı Karakterizasyonu ve Mekanik Özellikleri

dönüşümleri sonrası bu bölgede tespit edilmiş olan Widmanstatten ferrit (WF) ve sementit kümesi içeren ferrit (FC) yapılarının varlığıdır. Kaynak bölgesindeki bu sertlik artışı sonucu sünekliğin düşük olması ve ayrıca kaynaklı bağlantının St52 tarafının (bu numune boyunun yarısına tekabül etmektedir) çekme deneyi boyunca elastik bölgede kalması sonucu toplam uzama değerine katkısının olmaması nedeniyle \% uzama değeri düşük seviyelerde kalmıştır. Kopma sertliğin en düşük olduğu bölge olan St37 ana malzeme tarafındaki ısıdan etkilenen bölgede (IEB'de) gerçekleşmiştir.

Tablo 1. Çekme deneyi sonuçları.

\begin{tabular}{c|c|c|c}
\hline Numune & $\begin{array}{c}\text { Akma } \\
\text { Dayanımı } \\
\text { (MPa) }\end{array}$ & $\begin{array}{c}\text { Çekme } \\
\text { Muk. } \\
(\mathrm{MPa})\end{array}$ & $\begin{array}{c}\text { Uzama } \\
(\%)\end{array}$ \\
\hline St37 & 250 & 373 & 45 \\
\hline St52 & 337 & 526 & 35 \\
\hline $\begin{array}{c}\text { SKK'lı } \\
\text { Numune }\end{array}$ & 272 & 389 & 9 \\
\hline
\end{tabular}

St37: St37 ana malzeme, St52: St52 ana malzeme, SKK'lı Numune: Sürtünme karıştırma kaynağı ile birleștirilmiş numune

\section{Sonuçlar}

$\mathrm{Bu}$ çalışma sonrasında elde edilen sonuçlar aşağıda özetlenmiştir:

1. Kalınlıkları $4 \mathrm{~mm}$ olan farklı iki yapı çeliğinde (St37 ve St52 çelik levhalarda) SKK kullanılarak $630 \mathrm{~min}^{-1}$ devir ve 65 mm.min ${ }^{-1}$ ilerleme hızında kaynak hatası içermeyen birleştirmeler elde edilmiştir.

2. Kaynak bölgesi, Widmanstatten ferrit, sementit kümesi içeren veya içermeyen ferrit ve tane sınırı ferriti gibi karmaşık yapılardan oluşmaktadır.

3. Kaynak bölgesinde sertliğin $347 \mathrm{HV}_{0,3}$ değerine kadar yükseldiği ve bu sertlik artışının sebebinin bu bölgedeki faz dönüşümleri ve tane incelmesi olduğu tespit edilmiştir.

4. Kaynak bölgesinin akma dayanımı $272 \mathrm{MPa}$ olarak tespit edilmiş olup bu değer iki ana malzemenin akma dayanımları (St37 250 MPa ve St52 337 $\mathrm{MPa}$ ) arasındadır. Kaynak bölgesinin çekme dayanımı da, 389 MPa olarak ölçülmüş olup bu değer de, St37 ana malzemenin çekme dayanımından (373 MPa) yüksek, St52 ana malzemenin çekme dayanımından (526 MPa) ise yaklaşık \% 25 daha düșüktür.

5. SKK ile birleştirilen St37/St52 levhaların, ana malzemelerin her ikisi ile karşılaștırıldığında yüzde uzama değerinin oldukça düşük seviyede (\%35 uzama değeri gösteren St52 ana malzemenin uzama değerine kiyasla \% 74 oranında daha düşük) olduğu tespit edilmiştir.

\section{Kaynakça}

[1] Thomas, W.M., Nicholas, E.D., Needham, J.C., Murch, M.G., Temple-Smith, P., Dawes, C.J. December 1991. International Patent Application No. PCT/GB92/02203 and GB Patent Application No. 9125978.8 and US Patent Application No. 5,460,317.

[2] Mishra, R.S., Ma, Z.Y. 2005. Friction Stir Welding and Processing, Materials Science and Engineering: R: Reports, Cilt 50, s. 1-78. DOI: 10.1016/j.mser.2005.07.001

[3] Nandan, R., DebRoy, T., Bhadeshia, H.K.D.H. 2008. Recent Advances in Friction-Stir Welding - Process, Weldment Structure and Properties, Progress in Materials Science, Cilt 53 (6), s. 980-1023. DOI: 10.1016/j.pmatsci.2008.05.001

[4] Çam, G., 2011. Friction Stir Welded Structural Materials: Beyond AlAlloys, International Materials Reviews, Cilt 56, s. 1-48. DOI:10.1179/095066010X127772 05875750

[5] Çam, G., Mistıkoğlu, S. 2014. Recent Developments in Friction Stir Welding of Al-alloys, Journal of Materials Engineering and Performance (JMEPEG), Cilt 23 (6), 
G. İpekoğlu vd. / Sürtünme Karıştırma Kaynağıyla Birleştirilen St37/St52 Levhaların Mikroyapı Karakterizasyonu ve Mekanik Özellikleri

s. 1936-1953. DOI: the effect of temper condition on

10.1007/s11665-014-0968-x

[6] Çam, G., İpekoğlu, G. 2017. Recent Developments in Joining of Aluminium Alloys, The International Journal of Advanced Manufacturing Technology, Cilt 91 (5-8), s. 1851-1866. DOI: 10.1007/s00170-016-9861-0

[7] Çam, G., İpekoğlu, G., Serindağ, H.T. 2014. Effects of use of higher strength interlayer and external cooling on properties of friction stir welded AA6061-T6 joints, Science and Technology of Welding and Joining, Cilt 19 (8), s. 715-720. DOI:

10.1179/1362171814Y.00000002 47

[8] İpekoğlu, G, Çam, G. 2014. Effects of initial temper condition and postweld heat treatment on the properties of dissimilar frictionstir-welded joints between AA7075 and AA6061 aluminum alloys, Metallurgical and Materials Transactions A, Cilt 45A (7), s. 3074-3087. DOI:10.1007/s11661014-2248-7

[9] İpekoğlu, G., Erim, S. Çam, G. 2014 Investigation into the influence of post-weld heat treatment on the friction stir welded AA6061 Alalloy plates with different temper conditions, Metallurgical and Materials Transactions A, Cilt 45A (2), s. 864-877. DOI: 10.1007/s11661-013-2026-y

[10] İpekoğlu, G. Erim, S., Çam, G. 2014. Effects of temper condition and post weld heat treatment on the microstructure and mechanical properties of friction stir butt welded AA7075 Al-alloy plates, The International Journal of Advanced Manufacturing Technology, Cilt 70 (1), s. 201-213. DOI: $10.1007 / \mathrm{s} 00170-013-5255-8$

[11] İpekoğlu, G., Erim, S. Gören Kıral, B., Çam, G. 2013. Investigation into friction stir weldability of AA6061 Al-alloy plates, Kovove materialy Metallic Materials, Cilt 51 (3), s. 155-163. DOI: $10.4149 / \mathrm{km}-2013-$ 3-155

[12] Bozkurt, Y., Salman, S., Çam, G. 2013. The effect of welding parameters on lap-shear tensile properties of dissimilar friction stir spot welded AA5754-H22/2024T3 joints, Science and Technology of Welding and Joining, Cilt 18 (4), S. 337-345. DOI: 10.1179/1362171813Y0000000111.

[13] İpekoğlu, G., Gören Kıral, B., Erim, S., Çam, G. 2012. Investigation of the effect of temper condition friction stir weldability of AA7075 Al-alloy plates, Materiali in Tehnologije/Materials and Technology, Cilt 46 (6), s. 627-632. DOI: 669.715:621.791:620.17

[14] Çam, G., Güçlüer, S., Çakan, A., Serindağ, H.T. 2009. Mechanical properties of friction stir buttwelded Al-5086 H32 plate, Materialwissenschaft und Werkstofftechnik, Cilt 40 (8), s. 638-642 DOI: $10.1002 /$ mawe.200800455.

[15] Xie, G.M., Ma, Z.Y., Geng, L. 2008. Effect of microstructural evolution on mechanical properties of friction stir welded ZK60 alloy, Materials Science and Engineering: A, Cilt A486 (1-2), s. 49-55. DOI: 10.1016/j.msea.2007.08.043

[16] Afrin, N., Chen, D.L., Cao, X., Jahazi, M. 2008. Microstructure and tensile properties of friction stir welded AZ31B magnesium alloy, Materials Science and Engineering: A, Cilt A472 (1-2), s. 179-186. DOI: 10.1016/j.msea.2007.03.018

[17] Yang, J., Xiao, B.L., Wang, D., Ma, Z.Y. 2010. Effects of heat input on tensile properties and fracture behavior of friction stir welded Mg- 
G. İpekoğlu vd. / Sürtünme Karıştırma Kaynağıyla Birleştirilen St37/St52 Levhaların Mikroyapı Karakterizasyonu ve Mekanik Özellikleri

3Al-1Zn alloy, Materials Science and Engineering: A, Cilt A527 (3), s. 708-714. DOI: 10.1016/j.msea.2009.09.044

[18] Küçükömeroğlu, T., Şentürk, E., Kara, L., İpekoğlu, Çam, G. 2016. Microstructural and mechanical properties of friction stir welded nickel-aluminum bronze (NAB) alloy', Journal of Materials Engineering and Performance (JMEPEG), Cilt 25 (1), s. 320-326. DOI: $10.1007 / \mathrm{s} 11665-015-1838-\mathrm{x}$

[19] Çam, G., Mistikoglu, S., Pakdil, M. 2009. Microstructural and mechanical characterization of friction stir butt joint welded $63 \% \mathrm{Cu}-37 \% \mathrm{Zn}$ brass plate, Welding Journal, Cilt 88 (11), s. 225s-232s.

[20] Çam, G., Serindağ, H.T., Çakan, A., Mistıkoğlu, S., Yavuz, H. 2008. The effect of weld parameters on friction stir welding of brass plates, Materialwissenschaft und Werkstofftechnik, Cilt 39 (6), s. 394-399. DOI: 10.1002/mawe.200800314

[21] Park, H.S., Kimura, T., Murakami, T., Nagano, Y., Nakata, K., Ushio, M. 2004. Microstructures and mechanical properties of friction stir welds of $60 \% \quad \mathrm{Cu}-40 \% \mathrm{Zn}$ copper alloy, Materials Science and Engineering: A, Cilt A371 (1-2), s. 160-169. DOI: 10.1016/j.msea.2003.11.030

[22] Fujii, H., Ueji, R., Takada, Y., Kitahara, H., Tsuji, N., Nakata, K. vd. 2006. Friction Stir Welding of Ultrafine Grained Interstitial Free Steels, Materials Transactions, Cilt 47, s. 239-242. DOI: $10.2320 /$ matertrans.47.239

[23] Fujii, H., Cui, L., Tsuji, N., Maeda, M., Nakata, K., Nogi, K. 2006. Friction stir welding of carbon steels, Materials Science and Engineering: A, Cilt 429, s. 50-57. DOI: 10.1016/j.msea.2006.04.118
[24] Küçükömeroğlu, T., Aktarer, S.M., İpekoğlu, G., Çam, G. 2016. Sürtünme Karıștırma Kaynaklı St 52 Çelik Bağlantıların İçyapı ve Mekanik Özelikleri, 16. Uluslararası Malzeme Sempozyumu (IMSP'2016), 12-14 Ekim, Denizli, 1500-1507.

[25] Lienert, T.J., Stellwag JR., Grimmett, B.B., Warke, R.W. 2003. Friction stir welding studies on mild steel, Supplement to the Welding Journal, Cilt 82, s. s1-s9.

[26] Cui, L., Fujii, H., Tsuji, N., Nogi, K. 2007. Friction stir welding of a high carbon steel, Scripta Materialia, Cilt 56, s. 637-640. DOI: 10.1016/j.scriptamat.2006.12.004

[27] Imam, M., Ueji, R., Fujii, H. 2015. Microstructural control and mechanical properties in friction stir welding of medium carbon low alloy S45C steel, Materials Science and Engineering: A, Cilt 636, s. 2434.

DOI: 10.1016/j.msea.2015.03.089

[28] Cui, L., Fujii, H., Tsuji, N., Nakata, K., Nogi, K., Ikeda, R., Matsushita, M. 2007. Transformation in Stir Zone of Friction Stir Welded Carbon Steels with Different Carbon Contents, ISIJ International, Cilt 47, s. 299-306. DOI: 10.2355/isijinternational.47.299

[29] Ozekcin, A., Jin, H.W., Koo, J.Y., Bangaru, N.V., Ayer, R., Vaughn, G. 2004. A Microstructural Study of Friction Stir Welded Joints of Carbon Steels, International Journal of Offshore and Polar Engineering, Cilt 14 (4), s. 284-288.

[30] Choi, D.H., Ahn, B.W., Yeon, Y.M., Park, S.H.C., Sato, Y.S., Kokawa, H. vd., 2011. Microstructural Characterizations Following Friction Stir Welding of Dissimilar Alloys of Low- and High-Carbon Steels, Materials Transactions, Cilt 52, S. 1500-1505. DOI: 10.2320/matertrans.M2010438 
G. İpekoğlu vd. / Sürtünme Karıștırma Kaynağıyla Birleştirilen St37/St52 Levhaların Mikroyapı Karakterizasyonu ve Mekanik Özellikleri

[31] Choi, D.-H., Lee, C.-Y., Ahn, B.-W., Yeon, Y.-M., Park, S.-H.C., Sato, Y.-S., vd. 2010. Effect of fixed location variation in friction stir welding of steels with different carbon contents, Science and Technology of Welding and Joining, Cilt 15, s. 299-304.

DOI:

$10.1179 / 136217109 X 1257781448$ 6737

[32] Küçükömeroğlu, T., Aktarer, S.M., İpekoğlu, G., Çam, G. 2015. Sürtünme Karıștırma Kaynaklı St 37-St 44 Alın Bağlantıların İçyapı ve Mekanik Özeliklerinin İncelenmesi, TMMOB Makina Mühendisleri Odası 9. Ulusal Kaynak Kongresi ve Sergisi, 20-21 Kasım, Ankara, 425-434.

[33] Kocańda, D., Hutsaylyuk, V., Slezak, T., Torzewski, J., Nykyforchyn, H., Kyryliv, V. 2012. Fatigue crack growth rates of S235 and S355 steels after friction stir processing, Materials Science Forum, Cilt 726, S. 203-210. DOI: 10.4028/www.scientific.net/MSF.7 26.203

[34] Da Silva, A.L.L. 2015. Advanced methodologies for the fatigue analysis of representative details of metallic bridges. University of Porto, Faculty of Engineering, Doctoral Thesis, 418s, Porto.

[35] Černý, I., Sís, J., Zháňal, P. 2016. Fatigue resistance of laser welded S355 steel sheet, Key Engineering Materials, Cilt 665, s. 69-72. DOI: 10.4028/www.scientific.net/KEM. 665.69

[36] Threadgill, P.L. 2007. Terminology in friction stir welding, Science and Technology of Welding and Joining, Cilt 12, s. 357-360. DOI: 10.1179/174329307X197629

[37] Thewlis, G. 2004. Classification and quantification of microstructures in steels, Materials Science and Technology, Cilt 20, s. 143-160. DOI:

10.1179/026708304225010325

[38] He, X., Gu, F., Ball, A. 2014. A review of numerical analysis of friction stir welding, Progress in Materials Science, Cilt 65, s. 1-66. DOI: 10.1016/j.pmatsci.2014.03.003 